very questionable. Therefore, it is assumed by many writers that the infection might possibly come from the lymph channels between the cord itself and the pia. But that seems to be very doubtful at the present time, so far as any anatomical explanation is concerned. As to the neuronophagia, he thinks there is a possible explanation for the varieties of the cells found in the infiltration. Numerous writers have claimed to be able to demonstrate inflammatory cells which have burrowed into the substance of a ganglion cell and the ganglion cell itself having gradually disappeared, then the lymphocyte or lymphocyte-like cells increased in their protoplasm at the expense of the ganglion cell and the nuclei stained a deeper blue color with various stains. In other words a deeper staining reaction of the nucleus. Here may be a possible explanation for the many different varieties of cells seen in this form of inflammation which has puzzled everyone so far. No one seems to have arrived at any definite conclusion as to where they come from.

\title{
NEW YORK NEUROLOGICAL SOCIETY
}

\section{April 7, 1908}

\author{
The President, DR. B. SACHS, in the Chair
}

\section{A. CASE OF REFRIGERATION BELL'S PALSY ACCOMPANIED BY LATERAL OSCILLATION OF THE EYEBALL}

\section{By L. Pierce Clark, M.D.}

The patient was a boy with complete refrigeration Bell's palsy of the right side of the face of ten months' duration. The case was of special interest because of a peculiar lateral oscillation of the right eyeball during a forceful attempt to close the eyes. This movement of the eyeball appeared to be largely induced by the internal rectus at the beginning of the act in closing the eyes. At the beginning the right eyeball was moved inward and upward, as was usual in these cases. The movement was no sooner begun than the lateral see-saw nystagmoid movement began. The left eye also exhibited the same movement but in a much less degree, and was partly under the control of the will. It might be inhibited at the beginning or end of the attempt on closure, but not while the strongest effort was being put forth. The lateral oscillation occurred only on attempt. to close the eyes; no other facial movement brought it out. Schlesinger recently reported a similar phenomenon in a medullary lesion of the seventh and twelfth nuclei, which gradually passed away as the primary lesion improved. Dr. Clark said that so far as he was aware, this was the first report of a case of the occurrence of this form of eye movement in a typical case of Bell's palsy. The explanation of this eye symptom was that a voluntary impulse attempted transmission over the seventh nerve, but being blocked by the palsy lesion, it overflowed by way of the posterior longitudinal bundle into the third nucleus. It was known that the movements of all extrinsic muscles of the eyes were so closely related, that some anatomists claimed a common nuclear origin for all muscles of the eye; that is, that the orbicularis palpebrarum partly originated in the hinder portion of the third nucleus. The internal rectus being the strongest intrinsic eye muscle whose movement was most inti- 
mately associated with the action of the orbicular was the explanation for the kind of eye movement shown in this case.

Dr. I. Abrahamson after examining the case shown by Dr. Clark, called attention to the fact that the right external rectus was also apparently affected. There was decided nystagmus as the eye was swung to the right.

Dr. Henry H. Tyson said he considered Dr. Abrahamson's observation incorrect, inasmuch as what Dr. Abrahamson thought was a paralysis of the right external rectus muscle was not a true paralysis; but only a limitation of the conjugate movement to the right.

Dr. Tyson thought that Dr. Clark's explanation was partly correct; but it did not account for the excessive nystagmic movement to the left.

Dr. Tyson had examined the eyes in this case for Dr. Clark and had reported the following condition and theory. Vision in right eye varied from $20 / 40$ to $20 / 20$, due to spasm of accommodation. Left eye, 20/20. Sensibility of cornea, right diminished, left normal. Motility of each eye tested separately apparently normal. Conjugate movements to left exceed those to right by fifteen degrees. Orthophoria for distance, very slight exophoria $\left(0.5^{\circ}\right)$ for near. Fusion power of muscles tested by prisms for distance-adduct. $12^{\circ}$, abduct. $4^{\circ}$, sursumduct. $3^{\circ}$, deorsumduct. $3^{\circ}$. Candle test shows no muscle palsics.

Upon forced movements of eyes to extreme right or left a slight psuedo-nystagmus was produced, sometimes horizontal, other times mixed. Upon attempting to forcibly close right eyelids, the eyes move up and to the left, and horizontal oscillatory movements ensue with the eyes moving through an area of about $35^{\circ}$, extending from a point five degrees from the right of the median line to a point about $30^{\circ}$ to the left of the median line. This movement seemed to be due to overflow stimuli from the facial nuclei to the third nerve nuclei through the posterior longitudinal fasciculi, and also to the centers for associate movements. The congugate movement to the left in this case being the stronger, we thus obtain the nystagmic movement in that direction. H. Schlesinger, who reported a somewhat similar case (Ncurol. Ccutralbl., No. 26, p. 242), stated that in all probability the horizontal movements of the eyeballs were due to central disturbances of innervation. An analysis of this case would show that it was due to overflow stimuli, as heretofore stated, and an insufficiency in the congugate movements to the right. The pupils in this case were at times equal, at other times unequal, the right being the smaller, due to spasm of the sphincter pupilla. Light and convergence reflex normal. Orbicularis lid reaction positive. Sensory reflex positive, more marked on left side. Psychic positive. Color field test gave the red field largest, then green and white being the smallest, indicating a hysterical element as a complication.

Dr. R. A. Diffendorf, of New Haven, Conn. said he had observed identical nystagmus-like movements in cases of catatonic stupor whenever the closed eyelids were forcibly opened. This symptom had been encountered so uniformly that it had come to be regarded as a characteristic symptom of catatonic stupor. This symptom had been discovered during an extensive study of eye movements in the insane carried on during the past year by Dodge and himself. Th1s far they had been unable to explain its origin. It is possible that Dr. Clark's case may throw some additional light on this matter.

Dr. M. Allen Starr recalled one case of typical Bell's palsy in which 
these oscillatory movements of the eyeball were present on attempting to close the eye. The phenomenon gradually disappeared.

\title{
A CASE OF NEURALGIA LIMITED TO THE SENSORY FILA- MENT OF THE SEVENTH NERVE
}

\author{
By M. Allen Starr, M.D.
}

The patient was a young woman, the wife of a physician, who was suffering from an intense type of neuralgia, the pain being absolutely limited to the sensory filament of the seventh nerve, which supplied the anterior surface of the auditory canal and a part of the external ear. The observation was interesting on account of the strict limitation of the pain, corresponding as it did with the area which Dr. J. Ramsay Hunt had described in connection with his cases of facial palsy following herpes auricularis. In his case, Dr. Starr said, there was a noticeable flattening of the face on the affected side, which rather strengthened the diagnosis of a disease of the facial nerve.

Dr. J. Ramsay Hunt said that while he had not seen a case of idiopathic neturalgia of the sensory mechanism of the seventh cranial nerve, these cases have been collected and described in his article in the Archives of Otology for December, 1907, "Otalgia Considered as an Affection of the Seventh Cranial Nerve."

There was, in his opinion, no question but that Dr. Starr's case was one of primary tic douloureux of the seventh cranial nerve.

Dr. Hunt has observed reflex otalgias in the same distribution as well as post-herpetic otalgias following herpetic inflammation of the geniculate ganglion of the facial nerve.

In these cases the pain was likewise circumscribed as in Dr. Starr's case, to the depths of the ear, the auditory canal and the interior of the auricle.

At the present time he has a case under observation of a young woman, who has suffered from recurrent lancinating pains in the region of the left auricle and auditory canal for the past five months. These pains are gradually diminishing in intensity, and are typically neuralgic in character. The anditory mechanism is entirely free from any evidences of organic disease.

This otalgia followed an acute febrile disturbance and a small crop of vesicles on the posterior surface of the left auricle. This case was evidently post-herpetic in its origin and is interesting because of its long duration.

Dr. William M. Leszynsky, who had seen the patient whose history was reported by Dr. Starr, said he could confirm what had been said in regard to the character of the pain. It was apparently a very severe but an atypical form of trigeminal neuralgia.

\section{A CASE OF THROMBOSIS OF THE POSTERIOR INFERIOR CEREBELLAR ARTERY}

By I. Abrahamson, M.D.

The patient was a man, 44 years old, a native of Russia and a tailor by occupation. His previous history was unimportant. He had been 